\title{
Mechanical Properties of Fabrics from Cotton and Biodegradable Yarns Bamboo, SPF, PLA in Weft
}

\author{
Živa Zupin and Krste Dimitrovski \\ University of Ljubljana, Faculty of Natural Sciences and Engineering, \\ Department of Textiles \\ Slovenia
}

\section{Introduction}

Life standard is nowadays getting higher. The demands of people in all areas are increasing, as well as the requirements regarding new textile materials with new or improved properties which are important for the required higher comfort or industrial use. The environmental requirements when developing new fibres are nowadays higher than before and the classical petroleum-based synthetic fibres do not meet the criteria, since they are ecologically unfriendly. Even petroleum as the primary resource material is not in abundance. The classical artificial fibres, e.g. polypropylene, polyacrylic, polyester etc, are hazardous to the environment. The main problems with synthetic polymers are that they are non-degradable and non-renewable. Since their invention, the use of these synthetic fibres has increased oil consumption significantly, and continues even today. It is evidenced that polyester is nowadays most frequently used among all fibres, taking over from cotton. Oil and petroleum are non-renewable (non-sustainable) resources and at the current rate of consumption, these fossil fuels are only expected to last for another 50-60 years; the current petroleum consumption rate is estimated to be 100,000 times the natural generation rate (Blackburn, 2005).

Environmental trends are more inclined to the development of biodegradable fibres, which are environment-friendly. A material is defined as biodegradable if it can be broken into simpler substances (elements and compounds) by naturally occurring decomposers essentially, anything that can be ingested by an organism without harming the organism. It is also necessary that it is non-toxic and decomposable in a relatively shot period on a human time scale (Blackburn, 2005). The biodegradability of fibres also depends on their chemical structure, molecular weight and super-molecular structure.

Biodegradable polymers can be classified into three main groups, i.e.:

- natural polysaccharides and biopolymers (cellulose, alginates, wool, silk, chitin, soya bean protein),

- $\quad$ synthetic polymers, esp. aliphatic polyesters (poly (lactic acid), poly (ع-caprolactone)), and

- $\quad$ polyesters produced by microorganisms (poly (hydroxyalkanoate)s) (Blackburn, 2005).

All known natural fibres are biodegradable; however, they have some disadvantages in the growing up and production processes. At growing cotton and other vegetable fibres, large amounts of pesticides are used which has a negative influence on the environment. 
In the research, three biodegradable fibres, i.e. bamboo fibres, fibres form polylactic acid (PLA) and soybean protein fibres (SPF) were used for which the industrial procedures already exist. At the same time, there are enough natural resources for the latter and they are environment-friendly. The physical-mechanical properties of fabrics with biodegradable yarns in weft and cotton yarns in warp were researched. We would like to determine whether and to what extent physical and mechanical properties change and whether they are acceptable in terms of today's criteria.

The researchers have been investigating and researching the production of biodegradable fibres and their properties. This research focuses on the mechanical properties of yarns made prom biodegradable fibres and first of all, on the mechanical properties of woven fabrics made from biodegradable yarns in weft and cotton yarns in warp. The latter is the most common way of producing woven fabrics, since the warp threads do not need to be changed.

\section{Properties of bamboo, PLA and SPF fibres}

New trends are being sought for naturally renewable resources in order to protect the nature. With the help of chemical processes, new biodegradable materials can be produced. Such materials can successfully replace or improve the existing artificial or natural materials. Many different sources can be used to produce biodegradable materials. Fibres from naturally renewable resources are made chemically as fibres from polylactic acid (PLA fibres) or as a secondary product of other technologies. Such products are soybean fibres, which are made from soy proteins after the extraction of oil from soybean. New, natural resources are also used for fibre-making purposes, e.g. bamboo tree for bamboo fibres. These are by far not the only existing fibres from renewable resources; nevertheless, in our research, these three types of yarns are used. All presented fibres have compatible properties with classical natural fibres and some additional properties with a good influence on the comfort of clothing to the human body.

\subsection{Bamboo fibres}

Bamboo is considered by many to be the ultimate green material (Netravali, 2005). Since it is a fast growing plant, it can be harvested in as little as six weeks, although more typically in three to five years. Bamboo reproduces through its extensive system of rhizomes. As such, there is a continuous supply of bamboo, which meets the definition of a renewable resource. And, of course, it is also a sustainable material, capable of sustaining itself with minimal impact to the environment.

Bamboo can thrive naturally without using any pesticide. It is seldom eaten by pests or infected by pathogen.

The bamboo fibre is a kind of regenerated cellulose fibre, which is produced from raw materials of bamboo pulp refined from bamboo through the process of hydrolysis-alkalization and multi-phase bleaching, then processed and pulp is turned into bamboo fibres.

The properties of bamboo fibre are:

- strong durability, stability and tenacity,

- thinness and whiteness degree similar to the classically bleached viscose,

- $\quad$ antibacterial and deodorizing in nature (even after being washed fifty times),

- incredibly hydroscopic (absorbing more water than other conventional fibres, e.g. cotton), 
- fabric garments make people feel extremely cool and comfortable in hot conditions,

- fabric is exceptionally soft and light, almost silky in feel, and

- fabric has a high level of breathability, for the cross-section of bamboo fibres is filled with various micro-gaps and -holes (Das, 2010 ).

\subsection{Polylactide fibres (PLA)}

Polylactic acid is a natural, biodegradable organic substance, which is harboured in the bodies of animals, plants and microbes. The polylactic acid as such cannot be found in the nature but needs to be industrially prepared with the lactic acid polymerisation.

The lactic acid used for the synthesis of polylactic acid is derived from genetically altered corn grains (Rijavec, Bukošek, 2009).

Unlike other synthetic fibre materials with vegetable resources (e.g. cellulose), PLA is well suited for melt spinning into fibres. Compared to the solvent-spinning process required for the synthetic cellulose fibres, melt spinning allows PLA fibres to be made with both lower financial and environmental cost, and enables the production of fibres with a wider range of properties (Dugan, 2000). The polymerisation occurs with the condensation of acid with alcohol, forming polyester. The misguidance in this observation is to assume that since PLA is polyester, it will behave in many ways similarly to PES or PA 6 fibres (Rekha et al., 2004).

The fundamental polymer chemistry of PLA allows control of certain fibre properties and makes the fibre suitable for a wide range of technical textile applications and special apparel (Farrington et al, 2005).

The properties of PLA fibre are:

- low moisture absorption,

- good natural regulation of the body temperature through moister absorption,

- low flammability,

- $\quad$ high resistance to UV and a low index of refraction, and

- $\quad$ excellent mechanical properties and module of elasticity (Lou et al., 2008).

\subsection{Soybean fibres}

Soy protein fibre (SPF) is the only plant protein fibre (Rijavec, Bukošek, 2009). It is a liquefied soy protein that is extruded from soybean after the extraction of oil, and processed mechanically to produce fibres by using new bioengineering technology. Fibres are produced by wet spinning, stabilized by acetylating, and finally cut into short staples after curling and thermoforming.

A soybean protein fibre has not only the superiorities of natural fibres but also the physical properties of synthetic ones.

The properties of SPF fibres are:

- noble appearance and similar look as silk fibres, however, they are considerably cheaper (Yi-you, 2004),

- very comfortable to wear, soft, smooth, with soft handle,

- fabric has the same moisture absorption as cotton fibres (Brooks, 2005),

- better moisture transmission than a cotton fabric, which makes it comfortable and sanitary,

- higher tensile strength than wool, cotton, and silk, however, lower than polyester fibres,

- does not shrink when washed in boiling water,

- outstanding anti-crease, easy-wash and fast-dry properties, 
- $\quad$ antibacterial properties, and

- high UV resistance.

In the table below, the physical and mechanical properties of fibres, e.g. length, fineness, dry tenacity, wet tenacity, dry breaking extension and physical density are shown.

\begin{tabular}{|l|c|c|c|c|c|c|c|c|c|}
\hline \multicolumn{1}{|c|}{ Properties } & Bamboo & Cotton & Viscose & PLA & PES & PA & SPF & Silk & Wool \\
\hline Length (mm) & $38-76$ & $25-45$ & $30-180$ & & $32-150$ & & $38-76$ & $\begin{array}{c}3.5 \cdot 10^{6}- \\
9 \cdot 10^{6}\end{array}$ & $50-200$ \\
\hline Fineness (dtex) & $1.3-5.6$ & $1.2-2.8$ & $1.3-25$ & & $1.3-22$ & & $0.9-3$ & $1-3.5$ & $4-20$ \\
\hline $\begin{array}{l}\text { Dry tenacity } \\
\text { (cN/dtex) }\end{array}$ & 2.33 & $1.9-3.1$ & $1.5-3.0$ & $3.2-5.5$ & $3-7$ & $3-6.8$ & $3.8-4.0$ & $2.4-5.1$ & $1.1-1.4$ \\
\hline $\begin{array}{l}\text { Wet tenacity } \\
\text { (cN/dtex) }\end{array}$ & 1.37 & $2.2-3.1$ & $0.7-1.11$ & & $2.4-7$ & $2.5-6.1$ & $2.5-3.0$ & $1.9-2.5$ & 1.0 \\
\hline $\begin{array}{l}\text { Dry breaking } \\
\text { extension (\%) }\end{array}$ & 23.8 & $7-10$ & $8-24$ & $20-35$ & $20-50$ & $26-40$ & $18-21$ & $10-25$ & $20-40$ \\
\hline Moisture regan (\%) & 13.3 & 8.5 & $12.5-13.5$ & $0.4-0.6$ & 0.4 & 4.5 & 8.6 & 11.0 & 14.5 \\
\hline Density (g/cm $\left.{ }^{3}\right)$ & $0.8-1.32$ & $1.5-1.54$ & $1.46-1.54$ & $\begin{array}{c}1.25- \\
1.27\end{array}$ & $\begin{array}{c}1.36- \\
1.41\end{array}$ & $\begin{array}{c}1.15- \\
1.20\end{array}$ & $\begin{array}{c}1.29- \\
1.31\end{array}$ & $\begin{array}{c}1.34- \\
1.38\end{array}$ & 1.32 \\
\hline
\end{tabular}

Table 1. Comparison of physical and mechanical properties of bamboo fibres, PLA, SPF, cotton, viscose, wool and PES

\section{Mechanical properties of woven fabrics}

With mechanical properties, the phenomenon on textile material is described which is a result of the material resistance on the activity of external forces causing the change of shape. The response of the textile material depends on the material properties, the way of load and its tension. With regard to the direction of the applied force, deformations at stretch and compression are known. To the mechanical properties of fabrics uniaxial or biaxial tensile properties, compression, shearing properties, bending rigidity, bursting and tear resistance can be listed.

Numerous parameters influence the mechanical properties of woven fabrics. Firstly, there are fibre properties, and their molecular properties and structure. The mechanical properties of fibres depend on their molecular structure, where macromolecules can be arranged in crystalline (unique arrangements of molecules) or amorphous (coincidental arrangements of molecules) structure. The macromolecules are orientated mostly along the fibre axis and are connected to each other with intermolecular bonds. When a force is applied, the supramolecular structure starts changing (Geršak, 2006).

The fibre properties and the type of spinning influence the yarn properties, while the fabric properties are also influenced by warp and weft density of the woven fabrics, and weave. The mechanical properties are also influenced by the weaving conditions, e.g. speed of weaving, warp insertion rate, weft beat-up force, the way of shed opening, warp preparation for weaving, warp and weft tension, number of threads in reed dent etc.

The properties of raw fabrics consequently depend on the construction and technological parameters. For the final use, raw fabrics have to be post-treated to add different functional properties. In most cases, these post-treatments worsen some mechanical properties, while again some other mechanical properties improve. In Figure 1, the procedure from fibres to the end of woven-fabric production is presented. 


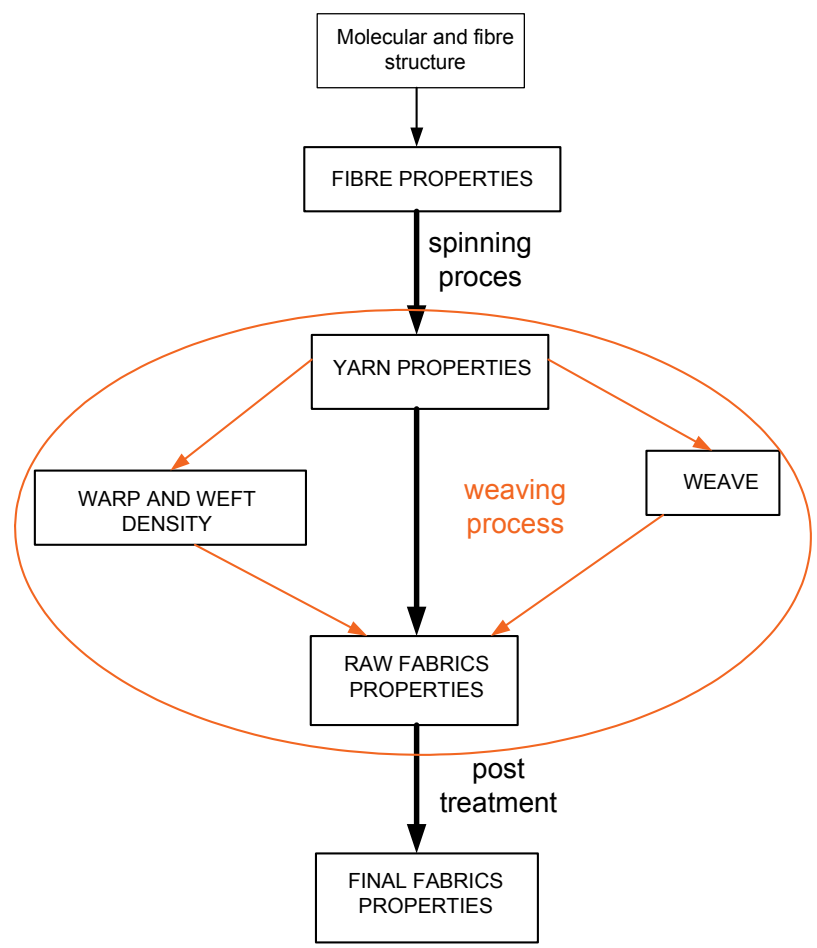

Fig. 1. Interrelation of fibre, yarn and fabric structure and properties

A lot of researches have been investigating the mechanical and tensile properties of fabrics. The approaches to the problem have included geometric, mechanical, energy and statistical models (Realff et al, 1997). The first geometric model of fabrics was presented by Pierce (Pierce, 1937), who presumed that yarn has an ideal circular cross section, which is rigid and inextensible. His work was continued by Womersley (Womersley, 1937), who presented a mathematical model of deformation of fabrics if exposed to a load. Similarly, other researchers have taken Pierce's work as a fundament. Kemp (Kemp, 1958) improved Pierce's model with the introduction of ecliptic shape of yarn. With the help of Pierce's and Kemp's geometry, Olofsson (Olofsson, 1965) presented a mechanical model of fabrics under uniaxial loading. His work was continued by Grosberg with co-authors (Grosberg et al, 1966), who were investigating tensile, bending, bulking and shearing properties, and fabrics and forces acting at counted properties on a fabric and yarn in the fabric. Kawabata approached the geometry of the interlacing point. He set the interlacing point in space, presented it as a space curve, and researched how the fabric behaves when forces act upon it and what deformations occur (Kawabata, 1989). Apart from the geometric and mechanical models, the researchers have also developed energy, statistical and numerical models of woven fabrics. In more recently, many researches are still based on the already known models, trying to improve or reform the already existed models. A lot of researchers have performed work based on real woven fabrics, studying their physical and mechanical properties. They have been investigating the influence of differently used yarn (material or different technique of spinning), the influence of different density of warp and weft threads, and weave. 
Our research is also based on the investigation of the physical and mechanical properties of woven fabrics with different yarns used in weft.

\subsection{Tensile properties of fabrics}

For designing apparel as well as for other uses, the knowledge about the tensile properties of woven fabrics is important. Strength and elongation are the most important performance properties of fabrics governing the fabric performance in use. Their study involves many difficulties due to a great degree of bulkiness in the fabric structure and strain variation during deformation. Each woven fabric consists of a large amount of constituent fibres and yarns and hence, any slight deformation of the fabric will subsequently give rise to a chain of complex movements of the latter. This is very complicated, since both fibres and yarns behave in a non-Hooken way during deformation $(\mathrm{Hu}, 2004)$

At the beginning of loading, extension occurs in amorphous parts, where primary and secondary bonds are extending and are shear loaded. If in this stage, an external force stops acting, most of the achieved extension will recover and the material shows elastic properties. If the loading continuous, a plastic deformation of the material occurs. Long chains of molecules are reciprocally re-arranged as a consequence of the disconnection of secondary bonds. The re-arrangements of the reciprocal position of molecules give material better possibility to resist additional loading. If the loading continuous, a final break will occur (Saville, 2002).

The stress-strain curve has three parts as it is shown in Figure 2. A higher initial module at a tensile test occurs, due to the resistance against friction and bending of fabrics. In the tested direction, in the direction of force, crimp yarns are straightened. When the yarns are straightened, the force in the fabrics increases quickly and fibres and yarns begin to extend, as it is shown in Figure $2 \mathrm{~b}$. The tensile properties of fabrics mostly depend on the tensile properties of yarns (Grosberg, 1969)

In the region of elasticity, where Hook's law exists, tenacity $(\sigma)$ is given with Equation 1.

$$
\sigma=\mathrm{E} \cdot \varepsilon
$$

Where:

$$
\begin{aligned}
& \sigma \text { - tenacity }\left(\mathrm{N} / \mathrm{mm}^{2}\right), \\
& \text { E - elastic or Young's module }\left(\mathrm{N} / \mathrm{mm}^{2}\right), \\
& \varepsilon \text { - extension - deformation }(\%) .
\end{aligned}
$$

A major difference between the shapes of the curves above occurs in the first part of the curve, i.e. in the Hook's zone (I - zone). This is influenced by a crimp of warp or weft yarns, when they begin to straighten. The elongation of the fabric is already increasing under a low force (still before the zone in which Young's modulus is calculated). Here, the crimp is interchanged between the threads of the two systems. The crimp decreases in the direction investigated, however, it increases in the perpendicular direction. Consequently, the tension of the threads of the system, which is perpendicular to the direction investigated, increases. When a tensile force acts on the threads of one system, the threads of both systems undergo extension. Due to the crimp interchange, the maximum possible elongation of perpendicular threads depends on the fabric geometry (Saville, 2002, Gabrijelčič et al, 2008).

The elastic or Young's module provides resistance against the deformation of the material (fabric). Lower the value of Young's module, the more deformable (extensible) is material. The Young's module in the diagram stress-strain represents the tangents of the inclination angle $\alpha$. The more resistant the material, the higher the angle of inclination $\alpha$. 


$$
E=\operatorname{tg} \alpha=\frac{\sigma}{\varepsilon}
$$
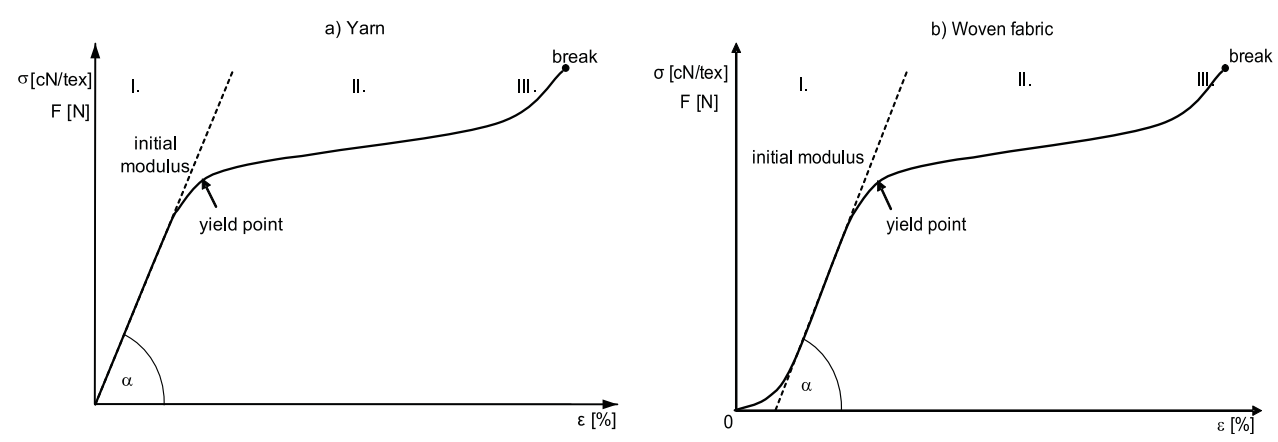

Fig. 2. Stress-strain curve of yarn and fabrics

As it can be seen in Figure 2, the load-extension curve is divided into three zones:

- the zone of elastic deformation or Hook's zone (zone I) of both yarn and fabric: If the extension occurs inside the Hook's zone, the material recovers to its initial length after the relaxation. This zone is also called the zone of linear proportionality or linear elasticity.

- $\quad$ the zone of viscoelastic deformation (zone II): After the loading, the material recovers to its initial length after a certain time of relaxation. The relationship between the stress and deformation is not linear. The limit between the elastic and plastic deformation is the yield point, on the stress-strain curve seen as a turn of curve.

- the zone of permanent deformations (zone III): The material does not recover after the relaxation (Geršak, 2006, Reallf et al, 1991)

\subsection{Mechanical properties measured with KES evaluation system}

Measuring other physical and mechanical properties and not only tensile properties is of great help in controlling and in the quality processes during the manufacture and posttreatment of textiles. Many researchers have been trying to develop a system for measuring the mechanical properties of textiles. The Kawabata Evaluation System (KES) is the first system for testing fabric mechanical properties. And it is also the system which evaluates fabric handle. This system has four different machines, and 16 parameters in warp and weft direction can be obtained, covering almost all aspects of physical properties of fabrics measured at small load. Tensile, bending, shearing, compressional and surface properties can be measured. From these measurements, properties such as stiffness, softness, extensibility, flexibility, smoothness and roughness can be inferred.

\section{Tensile property}

The tensile behavior of fabrics is closely related to the inter-fiber friction effect, the ease of crimp removal and load-extension properties of the yarn themselves as it was discussed before. Four tensile parameters can be determined through the KES instruments LT, WT, RT and EMT. LT represents the linearity of the stress-strain curve. A higher value of LT is supposed to be better. EMT reflects fabric extensibility, a measure of fabric ability to be 
stretched under a tensile load. The larger the EMT, the more extensible is the fabric (Chan et al, 2006). A proper amount of extensibility is desirable, while both excessive and insufficient extensibility will cause problems for the production. LT represents the linearity of the stress-strain curve. A higher value of LT is supposed to be better. WT denotes the tensile energy per unit area, taking care of the effect of both EM and LT. Thus, the conclusion about WT can be deduced from the comparison of EM and LT. RT (tensile resiliency) measures the recovery from tensile deformation. A tight fabric structure contributes to a better recovery.

\begin{tabular}{|l|l|l|l|}
\hline Property & Symbol & Parameter measured & Unit \\
\hline Tensile & LT & Linearity of load extension curve & $/$ \\
\hline & WT & Tensile energy & $\mathrm{cN} \mathrm{cm} / \mathrm{cm}^{2}$ \\
\hline & RT & Tensile resilience & $\%$ \\
\hline & EMT & Extensibility, strain at $500 \mathrm{cN} / \mathrm{cm}$ & $\%$ \\
\hline & G & Shear rigidity & $\mathrm{cN} / \mathrm{cm}$ degree \\
\hline & 2HG & Hysteresis of shear force at $0.5^{\circ}$ & $\mathrm{cN} / \mathrm{cm}$ \\
\hline Bending & 2HG5 & Hysteresis of shear force at $5^{\circ}$ & $\mathrm{cN} / \mathrm{cm}^{2}$ \\
\hline & B & Bending rigidity & $\mathrm{cN} \mathrm{cm} / \mathrm{cm}$ \\
\hline Compression & LC & Bending hysteresis & $\mathrm{cN} \mathrm{cm} / \mathrm{cm}$ \\
\hline & WC & Cinearity of compression thickness curve & $/$ \\
\hline & RC & Compressional resilience & $\mathrm{cN} \mathrm{cm} / \mathrm{cm}^{2}$ \\
\hline Surface & MIU & Coefficient of fabric surface friction & $\%$ \\
\hline & MMD & Mean deviation of MIU & $/$ \\
\hline & SMD & Geometric roughness & $\mu \mathrm{m}$ \\
\hline Thickness & T & Fabric thickness at $50 \mathrm{~N} / \mathrm{m}^{2}$ & $\mathrm{~mm}$ \\
\hline Weight & W & Fabric weight per unit area & $\mathrm{mg} / \mathrm{cm}^{2}$ \\
\hline
\end{tabular}

Table 2. Parameters measured on KES system

\section{Shear property}

Whenever bending occurs in more than one direction, so that the fabric is subjected to double curvature, shear deformations of the fabric are involved. As revealed by its definition, shear property is highly related to the fabric bending property. The shear property in conjunction with the bending property is thus a good indicator of the ability of a fabric to drape. A shear deformation is very common during the wearing process, since the fabric needs to be stretched or sheared to conform to the new gesture of a body movement. During the making-up of a garment, the shear deformation is also indispensable for an intended garment shape. Shear rigidity $G$ provides a measure of the resistance to the rotational movement of the warp and weft threads within a fabric when subjected to low levels of shear deformation. The lower the value of $G$, the more readily the fabric will conform to three-dimensional curvatures. If the shear rigidity is not enough, a fabric distortion will easily occur. So does the skewing or bowing during handling, laying up, and sewing. On the other hand, too high shear rigidity might also present a problem to form, mould, or shape, especially at the sleeve head. 2HG and 2HG5, the hysteresis of shear force at $0.5^{\circ}$ and $5^{\circ}$, are two other measures of the shear property of a fabric. Like $2 \mathrm{HB}$, the lower the $2 \mathrm{HG}$ and $2 \mathrm{HG} 5$, the better the recovery from shear deformation. 


\section{Bending property}

The fabric bending property is apparently a function of the bending property of its constituent yarns. Two parameters can be used to measure this property, i.e. $B$ and $2 \mathrm{HB}$. $B$ is bending rigidity, a measure of a fabric ability to resist to a bending deformation. In other words, it reflects the difficulty with which a fabric can be deformed by bending. This parameter is particularly critical in the tailoring of lightweight fabrics. The higher the bending rigidity, the higher the fabric ability to resist when it is bent by an external force, i.e. during fabric manipulation in spreading and sewing. Apart from for the bending rigidity of the constituent yarns and fibers, the mobility of the warp/weft within the fabric also comes into play in this aspect. In addition, the effect of density and fabric thickness are also very profound for this property. $2 \mathrm{HB}$ represents the hysteresis of the bending moment. It is a measure of recovery from bending deformations. A lower value of $2 \mathrm{HB}$ is supposed to be better.

\section{Compression}

Fabric compression is one of the most important factors when assessing fabric mechanical properties, since it is highly related to the fabric handle, i.e. fabric softness and fullness, and fabric surface smoothness. Especially, this property might even influence the thermal property of a fabric. For example, when a fabric is compressed, a subsequent drop in its thermal insulation will be found as well due to the loss of still air entrapped in the fabric. The compressional property can be influenced in many ways. Generally speaking, this property can reflect the integrated effect of a fabric structure like yarn crimp level and thickness, the constituent fiber and/or yarn surface property, and lateral compressional property. LC, the linearity of compression-thickness curve, WC, the compressional energy per unit area, and the last one $\mathrm{RC}$, the compressional resilience, reflect the ability of a fabric to recover from a compressional deformation.

\section{Surface property}

Apparently, the fabric handle bears a close relationship with the surface property of a fabric. Three parameters are used as indices of fabric surface property, i.e. MIU, the coefficient of friction, MMD, a measure of the variation of the MIU, and SMD, a measure of geometric roughness. MIU is mainly governed by the contact area and type of weave. The greater the contact area, the higher the MIU value. Generally, a plain weave exhibits a higher geometric roughness in comparison with twill weave due to its shorter floats. [5, 6]

\section{Experimental}

The research was focused on the mechanical properties of fabrics with cotton warp and biodegradable yarns (bamboo, PLA and SPF) as well as cotton in weft. Pure cotton fabrics were made for the comparison with other fabrics with biodegradable yarns in weft.

Fabrics were made in four most commonly used weaves (i.e. plain weave, basket weave, twill 1/3 and twill 2/2). All fabrics were made on the same loom with the same density for all fabrics, 30 threads/cm in warp and 28 threads/cm in weft. Fabrics were washed after desizing.

For all fabrics, the physical characteristic warp and weft crimp, mass per square meter, thickness of fabrics, as well as tensile properties of used yarns and tensile properties of fabrics in warp and weft direction were measured in compliance with the SIST EN ISO 13934 standard. For a better comparison between the fabrics with different materials in weft, 
breaking tenacity was calculated as well and presents how much force can yarn hold per linear density.

Moreover, other mechanical properties were measured on the KES system, e.g. bending, tensile properties at small load, shearing and compression. The measurements were statistically estimated and analyzed with multivariate statistical methods.

\begin{tabular}{|c|c|c|c|c|c|c|c|}
\hline & Weave & Warp & Weft & $\begin{array}{l}\text { Warp } \\
\text { crimp }\end{array}$ & Weft crimp & Mass & Thickness \\
\hline & & $\mathrm{Tt}_{1}$ (tex) & $\mathrm{Tt}_{2}$ (tex) & $C_{1}(\%)$ & $\mathrm{C}_{2}(\%)$ & $\left(\mathrm{g} / \mathrm{m}^{2}\right)$ & $(\mathrm{mm})$ \\
\hline 1 & Plain & \multirow{16}{*}{$\begin{array}{l}\text { Cotton } \\
28 \text { tex }\end{array}$} & \multirow{4}{*}{$\begin{array}{l}\text { Bamboo } \\
21 \text { tex }\end{array}$} & 9.24 & 13.32 & 170.83 & 0.163 \\
\hline 2 & Basket & & & 2.94 & 5.44 & 164.30 & 0.241 \\
\hline 3 & 1/3 Twill & & & 2.72 & 15.08 & 168.21 & 0.266 \\
\hline 4 & 2/2 Twill & & & 3.28 & 13.06 & 167.44 & 0.247 \\
\hline 5 & Plain & & \multirow{4}{*}{$\begin{array}{l}\text { PLA } \\
20 \text { tex }\end{array}$} & 8.86 & 17.74 & 174.42 & 0.203 \\
\hline 6 & Basket & & & 3.58 & 19.44 & 168.66 & 0.264 \\
\hline 7 & 1/3 Twill & & & 4.16 & 20.06 & 169.09 & 0.279 \\
\hline 8 & 2/2 Twill & & & 3.94 & 21.52 & 169.35 & 0.269 \\
\hline 9 & Plain & & \multirow{4}{*}{$\begin{array}{l}\text { SPF } \\
15 \text { tex }\end{array}$} & 8.04 & 23.32 & 156.93 & 0.162 \\
\hline 10 & Basket & & & 2.54 & 21.80 & 153.97 & 0.234 \\
\hline 11 & 1/3 Twill & & & 2.84 & 25.62 & 159.32 & 0.247 \\
\hline 12 & 2/2 Twill & & & 3.16 & 22.98 & 152.35 & 0.244 \\
\hline 13 & Plain & & \multirow{4}{*}{$\begin{array}{l}\text { Cotton } \\
19 \text { tex }\end{array}$} & 11.06 & 14.86 & 164.40 & 0.201 \\
\hline 14 & Basket & & & 2.34 & 13.46 & 158.58 & 0.281 \\
\hline 15 & 1/3 Twill & & & 3.36 & 14.70 & 161.61 & 0.283 \\
\hline 16 & 2/2 Twill & & & 3.76 & 15.86 & 161.80 & 0.278 \\
\hline
\end{tabular}

Table 3. Construction parameters of fabrics and measured physical parameters of fabrics

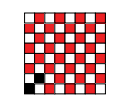

Plain weave (PL)

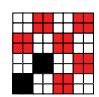

Basket weave (BW)

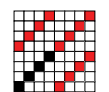

Twill 1/3 (T 1/3)

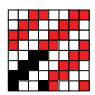

Twill 2/2 (T 2/2)

Fig. 3. Used weaves in fabrics

\section{Results}

\subsection{Tensile properties of yarns}

As said before, the strength of a fabric depends not only on the strength of the constituent yarn, but also on the yarn structure, yarn bending behaviour, fabric geometry, thus tensile properties (i.e. tensile force and tensile elongation) of all used yarns were measured and for a better comparison, breaking tenacity of yarns was calculated. It was established that SPF yarn is the strongest and can withstand the most stress per linear density. Warp and weft cotton yarns have almost the same breaking tenacity (i.e. around $16 \mathrm{cN} /$ tex). The breaking tenacity of PLA yarn is around $12.5 \mathrm{cN} /$ tex and the lowest is for bamboo yarns.

Furthermore, the tenacity-extension curves were elaborated for each yarn, where the stressstrain behaviour of the used materials can be observed. In Figure 2, it can be seen that 
biodegradable yarns differ from cotton yarns especially at tensile elongation, which is approximately two times (bamboo yarn), three times (SPF) and five times (PLA) higher than at cotton weft yarns. On the other hand, the tensile strength of weft cotton yarns is comparable with the tensile strength of bamboo and PLA, while the SPF yarn has a considerably higher tenacity.

\begin{tabular}{|l|r|r|r|r|r|}
\hline & $\begin{array}{c}\text { COTTON - } \\
\text { WARP }\end{array}$ & BAMBOO & PLA & SPF & $\begin{array}{c}\text { COTTON - } \\
\text { WEFT }\end{array}$ \\
\hline $\mathrm{F}(\mathrm{cN})$ & $\mathbf{4 4 4 . 3 8}$ & $\mathbf{2 1 8 . 8 4}$ & $\mathbf{2 4 9 . 7 7}$ & $\mathbf{2 8 7 . 2 2}$ & $\mathbf{2 5 8 . 4 9}$ \\
\hline $\mathrm{CV}$ & 8.44 & 12.32 & 8.03 & 8.39 & 9.21 \\
\hline $\mathrm{E}(\%)$ & $\mathbf{4 . 1 8}$ & $\mathbf{8 . 5 2}$ & $\mathbf{2 7 . 5 2}$ & $\mathbf{1 3 . 7 2}$ & $\mathbf{4 . 4 5}$ \\
\hline $\mathrm{CV}$ & 9.39 & 12.34 & 8.27 & 6.41 & 11.24 \\
\hline$\sigma(\mathrm{cN} /$ tex $)$ & 16.35 & 10.42 & 12.49 & 19.17 & 16.88 \\
\hline
\end{tabular}

Table 4. Tensile properties (breaking force, breaking elongation and breaking tenacity) of yarns used in fabrics

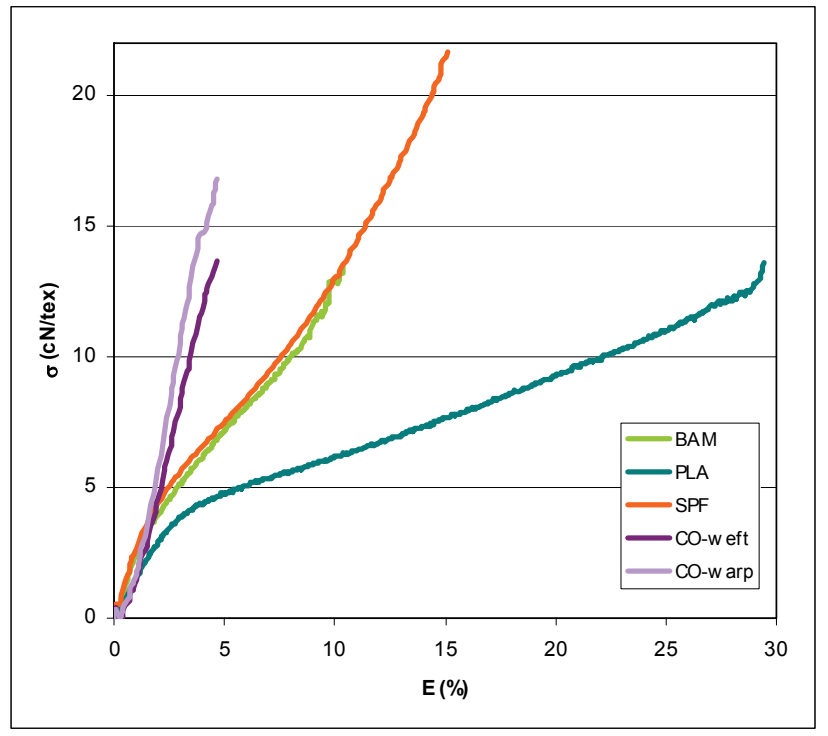

Fig. 4. Tenacity-extension curve for bamboo, PLA, SPF and cotton yarns

\subsection{Tensile properties of fabrics}

Tensile properties of all 16 fabrics were measured. The results of all measurements (breaking force and breaking elongation) are shown in Table 4 . Moreover, the breaking tenacity of one yarn in weft direction of the fabric was calculated for a better comparison of yarns with different linear densities.

Firstly, it was established that the type of weave has a greater influence on the breaking force of fabrics in warp direction than different types of yarns. With a multivariate statistical analysis, it was proved that weave is a 5-time more important factor than different material 
in weft. The highest tensile force is, as it was expected, in plain weave, due to the maximum number of interlacing points resulting in higher friction between yarns and consequently also higher tensile strength in warp direction. Twill 2/2, twill $1 / 3$ and basket weaves follow with lower values, which are presented in Figure 5. The differences in the same weave depend considerably on the material used in weft. It was found out that the extensibility of yarns in weft direction influences the breaking force in warp direction. The highest breaking force in warp direction is shown at fabrics with PLA and SPF yarn in weft and the lowest tensile force at pure cotton fabrics, since cotton yarn has the lowest elongation.

\begin{tabular}{|c|c|c|c|c|c|c|c|c|c|c|c|}
\hline \multirow[b]{2}{*}{ No } & & & \multicolumn{4}{|c|}{ WARP } & \multicolumn{5}{|c|}{ WEFT } \\
\hline & & & $\mathrm{F}(\mathrm{N})$ & $\mathrm{CV}$ & $\begin{array}{c}E \\
(\%)\end{array}$ & $\mathrm{CV}$ & $\mathrm{F}(\mathrm{N})$ & $\mathrm{CV}$ & $\begin{array}{c}\sigma \\
(\mathrm{cN} / \text { tex })\end{array}$ & E $(\%)$ & $\mathrm{CV}$ \\
\hline 1 & PL & \multirow{4}{*}{ Bamboo } & 903.75 & 1.24 & 13.95 & 2.06 & 322.13 & 3.3 & 54.78 & 19.58 & 4.26 \\
\hline 2 & BW & & 779.27 & 2.39 & 7.48 & 2.53 & 334.68 & 4.31 & 55.34 & 19.18 & 4.4 \\
\hline 3 & T1/3 & & 815.44 & 3.18 & 7.98 & 3.44 & 326.05 & 3.63 & 54.29 & 21.69 & 3.12 \\
\hline 4 & $\mathrm{~T} 2 / 2$ & & 812.6 & 4.43 & 7.83 & 2.68 & 350.98 & 2.42 & 59.69 & 21.99 & 2.74 \\
\hline 5 & $\overline{\mathrm{PL}}$ & \multirow{4}{*}{ PLA } & 907.77 & 3.44 & 15.82 & 2.51 & 376.91 & 3.91 & 63.67 & 44.14 & 4.36 \\
\hline 6 & BW & & 796.93 & 3.13 & 7.58 & 2.79 & 370.18 & 1.44 & 65.17 & 44.29 & 2.92 \\
\hline 7 & $\mathrm{~T} 1 / 3$ & & 806.68 & 2.92 & 7.93 & 1.7 & 360.12 & 1.46 & 64.31 & 46.6 & 2.04 \\
\hline 8 & $\mathrm{~T} 2 / 2$ & & 845.43 & 4.97 & 8.08 & 2.62 & 352.82 & 4.02 & 61.68 & 48.75 & 2.53 \\
\hline 9 & $\overline{\mathrm{PL}}$ & \multirow{4}{*}{ SPF } & 965.67 & 3.99 & 14.06 & 3.99 & 351.04 & 2.68 & 82.11 & 32.34 & 2.53 \\
\hline 10 & BW & & 779.76 & 1.74 & 6.22 & 3.43 & 347.26 & 7.24 & 80.38 & 30.87 & 6.1 \\
\hline 11 & $\mathrm{~T} 1 / 3$ & & 788.65 & 3.53 & 7.23 & 2.91 & 332.87 & 2.74 & 78.14 & 30.53 & 1.24 \\
\hline 12 & $\mathrm{~T} 2 / 2$ & & 817.92 & 1.8 & 6.98 & 2.97 & 340.38 & 4.88 & 78.79 & 33.19 & 4.93 \\
\hline$\overline{13}$ & PL & \multirow{4}{*}{ Cotton } & 857.76 & 5.39 & 15.16 & 2.52 & 474.14 & 2.64 & 85.76 & 16.16 & 1.77 \\
\hline 14 & BW & & 766.48 & 4.11 & \begin{tabular}{|l|}
7.13 \\
\end{tabular} & 4.04 & 424.42 & 5.75 & 79.49 & 16.82 & 16.86 \\
\hline 15 & $\mathrm{~T} 1 / 3$ & & 730.2 & 2.86 & 7.93 & 3.64 & 433.9 & 1.42 & 81.56 & 15.62 & 3.5 \\
\hline 16 & T2/2 & & 771.94 & 4.8 & $\begin{array}{l}7.58 \\
\end{array}$ & 2.77 & 451.16 & 2.1 & 84.20 & $\begin{array}{l}19.18 \\
\end{array}$ & 12.73 \\
\hline
\end{tabular}

Table 5. Tensile properties (breaking force, breaking elongation in warp direction and breaking force, breaking elongation and breaking tenacity in weft direction) of fabrics

Among the fabrics woven in plain weave, the fabric with SPF yarn in weft is distinguished with the highest breaking force $(965.67 \mathrm{~N})$ ), followed by the fabrics with PLA (907.77) and bamboo (903.75) yarn in weft. The lowest tensile strength belongs to the fabric with cotton yarn also in weft $(857.76 \mathrm{~N})$. In the case of basket weave, the difference between the highest value (fabric with PLA yarn in weft $-796.93 \mathrm{~N}$ ) and the lowest value (fabric with cotton yarn in weft $-766.48 \mathrm{~N}$ ) is small. Among the fabrics woven in twill 1/3, the highest breaking force is observed in the fabric with bamboo yarn in weft $(815.44 \mathrm{~N})$, and the lowest tensile strength again in the fabric with cotton also in warp (730.2 N). Among the fabrics woven in $2 / 2$ twill, the fabric with PLA yarn in weft has the highest value of tensile strength (845.43 N); the lowest tensile strength is observed, as in previous weaves, in the fabric with cotton weft (771.94 N).

The tensile force in weft direction influences mostly the material used in weft, while the weave has practically no influence. For a better comparison and understanding how different weft yarns influence tensile properties, esp. breaking force, the breaking tenacity of fabrics in weft direction was calculated and is presented in Figure 7.

From Figure 6, it can be seen that the highest breaking force characterises pure cotton fabrics, since weft cotton yarn has also high breaking tenacity of yarns, however, not the 
highest one. SPF yarns have the highest breaking tenacity $(19.17 \mathrm{cN} /$ tex); nevertheless, the fabrics have lower breaking force and also lower breaking tenacity calculated on one thread than pure cotton fabrics ( $83 \mathrm{cN} /$ tex). The breaking tenacity of SPF yarns in fabrics is approximately $80 \mathrm{cN} /$ tex. The reason could be that SPF yarns are much smoother than cotton yarns and less friction occurs between warp and weft yarns. The second highest breaking force in weft direction is typical of fabrics with PLA yarn in weft, although the breaking tenacity of PLA yarn $(12.49 \mathrm{cN} /$ tex $)$ and the breaking tenacity calculated on one thread in fabrics are lower than for cotton and SPF. The average breaking tenacity of all fabrics with PLA in weft is approximately $64 \mathrm{cN} /$ tex. It can be expected that the SPF fabrics with the same linear density of weft yarn will have higher tensile strength than the fabrics with PLA yarn in weft. The lowest breaking force in weft direction characterises the fabrics with bamboo yarn in weft. Bamboo yarn has the lowest tenacity $(10.42 \mathrm{cN} /$ tex $)$ and in fabrics, the breaking tenacity is approximately $56 \mathrm{cN} /$ tex.

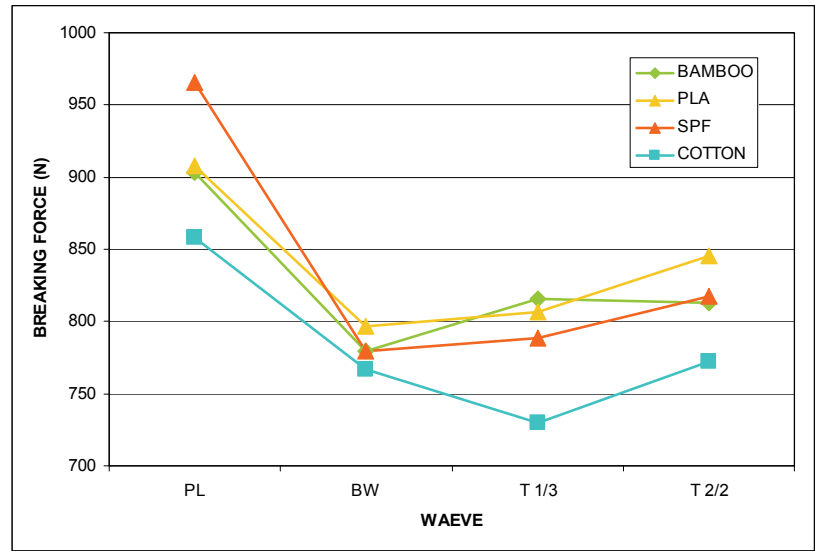

Fig. 5. Breaking force of fabrics in warp direction

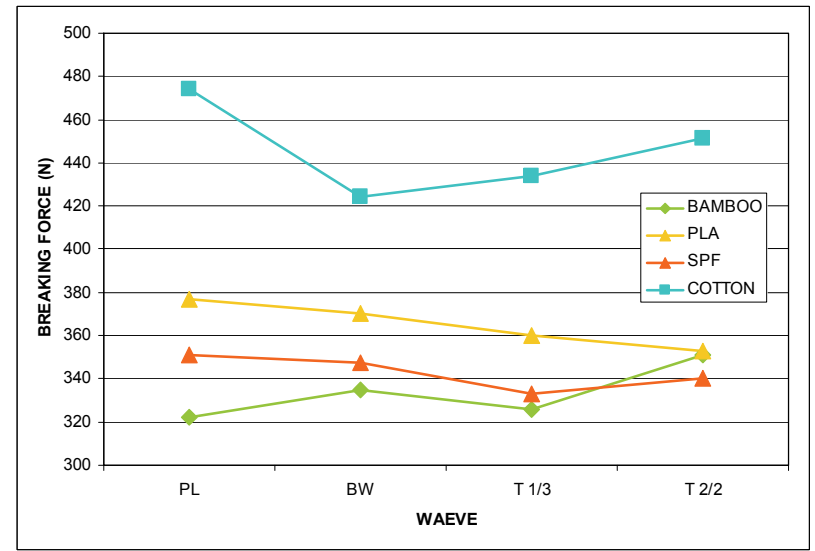

Fig. 6. Breaking force of fabrics in weft direction 


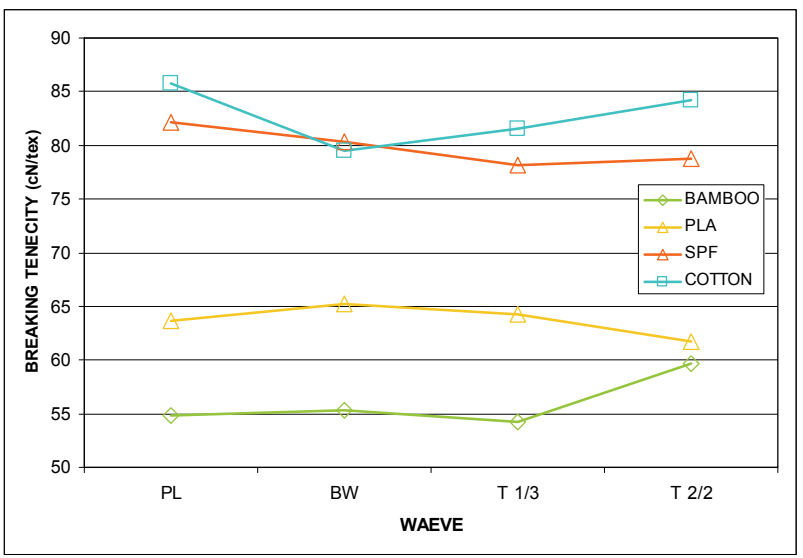

Fig. 7. Breaking tenacity of fabrics in weft direction

It was also found out that different properties of yarns have almost no influence on the tensile elongation of fabrics in warp direction, while mostly the weave type influences the tensile elongation in warp direction. The weave type is statistically 50 times more important than different materials used in weft. Figure 8 shows that fabrics in plain weave have the highest tensile elongation, which is approximately $15 \%$, whereas the tensile elongation of all other fabrics, as can be seen in the diagram, is about $7 \%$. Plain weave has the maximum number of interlacing points, which is twice as high as that of other weaves and, as a result, tensile elongation is higher. Also, warp crimp is the highest in plain weave, which influences tensile elongation as it was said before. The lowest tensile elongation is typical of the fabrics woven in basket weave.

Both the weave type and the material in weft influence the tensile elongation in weft direction, but the material used in weft is statistically 90 times more important. The highest tensile elongation is at fabrics with PLA yarns in weft, which are also the most extensible yarns. Then there are fabrics with SPF yarn, followed by fabrics with bamboo yarn and the lowest tensile elongation is at pure cotton fabrics, since cotton yarns have the lowest extensibility.

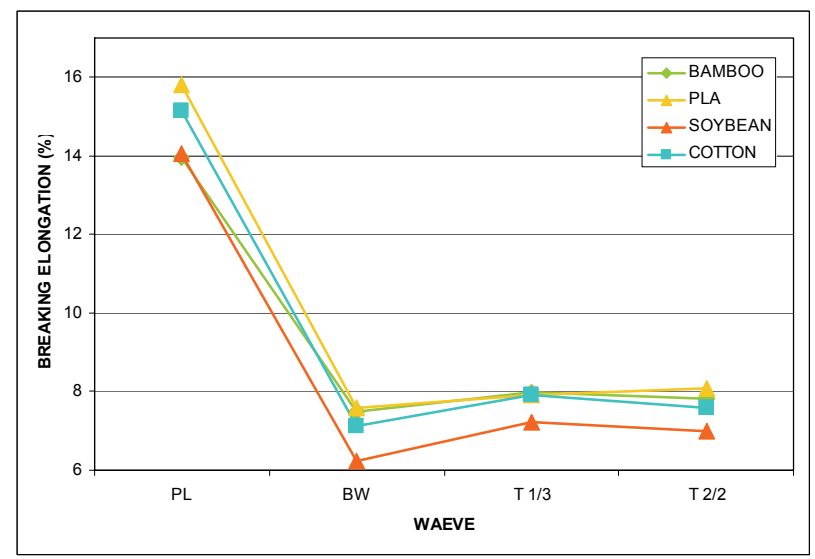

Fig. 8. Breaking elongation of fabrics in warp direction 


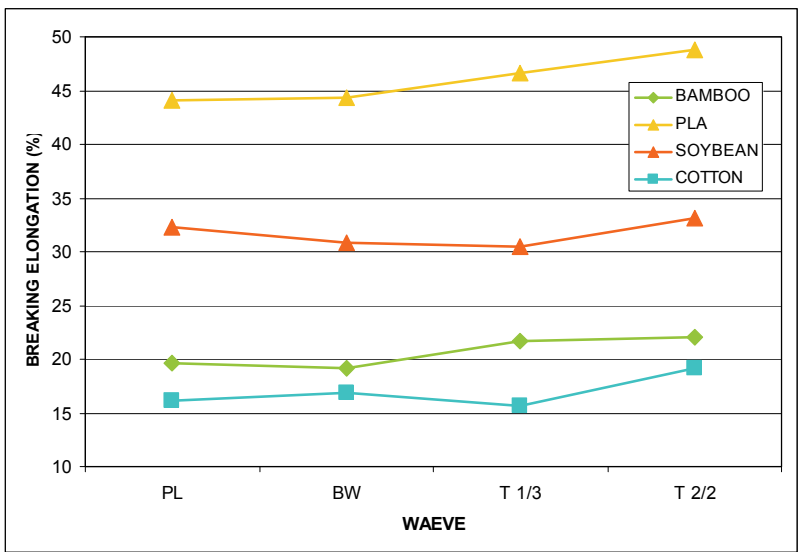

Fig. 9. Breaking elongation of fabrics in weft direction

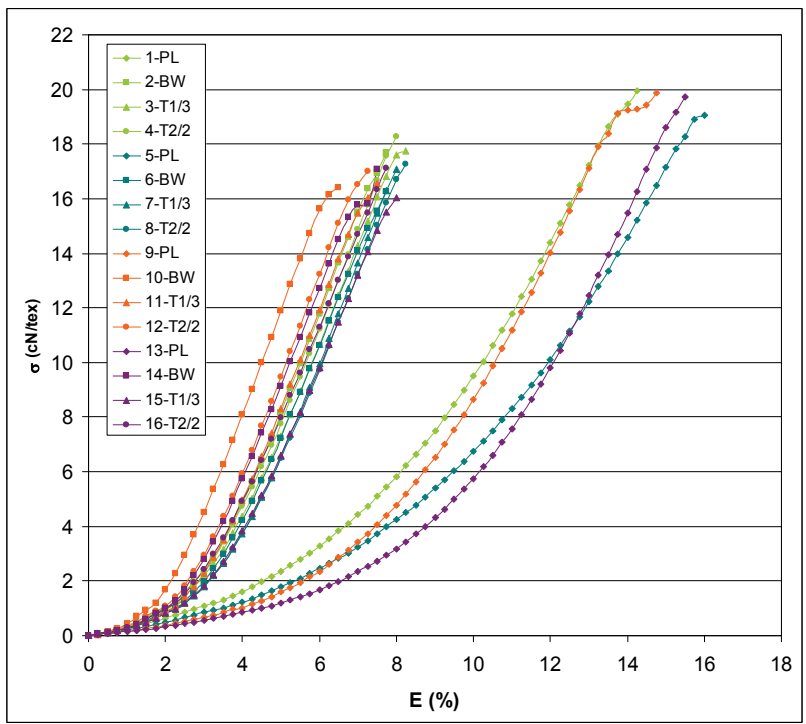

Fig. 10. Tenacity - extension curves for fabrics in warp direction

The fabrics with PLA yarn have the highest tensile elongation, for PLA yarn itself already has the highest tensile elongation $(27.52 \%)$ and is the most extensible yarn. All these fabrics have tensile elongation about $45 \%$. It is evident in Figure 9 that the fabrics in twill 1/3 and twill 2/2 have higher tensile elongation than plain and basket weave. The fabrics with SPF yarn in weft come in the second place. The tensile elongation of SPF yarn $(13.72 \%)$ is ranked second. Figure 8 also shows that tensile elongation of these fabrics is ca $32 \%$. The highest tensile elongation belongs to plain weave and twill 2/2 weave. Next to them, there are the fabrics with bamboo yarn with mean tensile elongation at about $20 \%$. The tensile elongation of bamboo yarn is $8.52 \%$. It is noticed again that twill $1 / 3$ and twill $2 / 2$ weaves have higher 
tensile elongation than the plain and basket weave. Cotton fabrics have the lowest tensile elongation, since the cotton yarn itself also has the lowest tensile elongation of only $4.45 \%$. The tensile elongation of cotton fabrics is $16 \%$. The highest elongation is observed in the fabric in twill 2/2 weave.

For all fabrics in warp and weft direction, tenacity-extension curves were made to compare different behaviour at the tensile test.

The tenacity-extension curves in Figure 10 show that it is the weave, which has the highest influence on the shape of curves in warp direction. The curves of plain weave have almost the same shape, whereas the shapes of other weaves have very similar shapes. All curves for each group of materials are arranged in a defined order, i.e. twill 1/3, twill 2/2 and basket. Plain weave has a completely different shape of the curve due to a more frequent interlacing of threads in the weave, which results in a higher shrinkage of the fabric and, consequently, higher elongation.

The shapes of the curves for weft show that it is solely the material, which influences the shape of the curve. The weave has practically no influence, which has already been proved by previous results. Each group of materials has its own specific shape of the curve. The fabrics with cotton weft have the most vertical shape of the curve, for they have the lowest tensile elongation. The fabrics with PLA yarn in weft have a very specific shape of the curve. If the tenacity-extension of yarns (cf. Figure 5) is compared with the tenacity-extension curve of fabrics, some similarities can be detected. However, if the curves are compared with the shapes of the curves of standard materials, i.e. cotton, cellulose, PES or PA, and silk, it can be stated that the curve with bamboo yarn in weft has the same shape of the curve as cellulose fibres. The shape of the curve with SPF yarn in weft is similar to the shape of the curve of silk. Cotton fabrics have the same shape of the curves as cotton fibres.

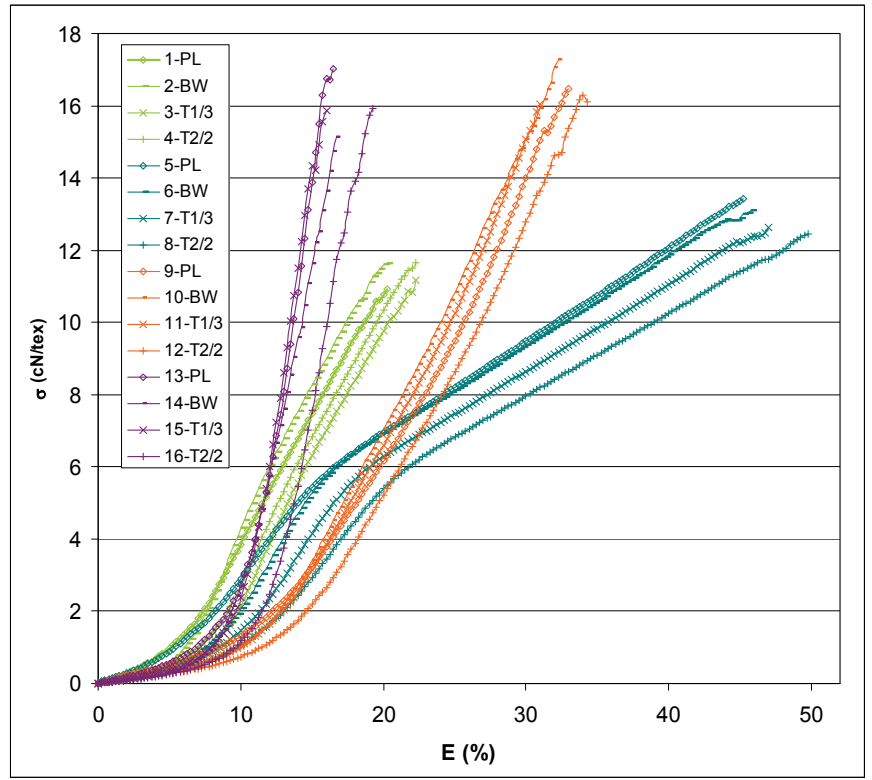

Fig. 11. Tenacity - extension curves for fabrics in weft direction 


\subsection{Other mechanical properties measured with KES evaluation system}

The measurements on the KES system show which of the investigated fabrics is the most suitable for the clothing industry and what kind of behaviour can be expected. From the results, it can be seen that fabrics with SPF yarn in weft are very extensible and flexible. Cotton fabrics are the softest and fabrics with bamboo weft have very similar properties as cotton fabrics.

As it was discussed above, the measurements of tensile properties on the KES system confirmed as well that the tensile behavior of fabrics is closely related to the inter-fiber friction effect, the ease of crimp removal and load-extension properties of the yarn themselves. The measurements of extensibility (EMT) of fabrics and tensile work (WT) show that as at tensile test, the weave mostly influences the tensile properties in warp, and the material used in weft the tensile properties in weft. At EMT, it can be seen that the highest extensibility characterizes the fabric with the SPF yarn in weft direction; however, the SPF yarn is not the most extensible material (13.72\%) but the fabric with the highest weft crimp, which has the highest influence on EMT. The fabrics in plain weave usually demonstrate a higher tensile work (WT), as it is also seen at our fabrics. It is also demonstrated that the fabrics wit SPF yarn in weft have the highest WT.

Shear rigidity $G$ provides a measure for the resistance to the rotational movement of warp and weft threads within a fabric when subjected to low levels of shear deformation. The lower the value of $G$, the more readily the fabric will conform to three-dimensional curvatures. If the shear rigidity is not enough, a fabric distortion will easily occur. Shear properties are most commonly influenced by weave, while the material used in weft has practically no influence.

The KES system tensile properties influence both the type of weave and the material used in weft. It was also established that some properties measured on the KES system have very good correlation with each other (e.g. thickness, and compressional properties, bending and shearing properties) and some properties inversely proportional (e.g. tensile energy and tensile resilience, bending and shearing properties, and compressional properties). If it is known which properties correlate with each other, it is easier to predict what kind of properties the fabric will fabrics.

\begin{tabular}{|l|lll|l|l|l|l|l|l|l|l|l|l|l|l|l|}
\hline & LT & WT & RT & EMT & G & 2HG & 2HG5 & B & 2HB & LC & WC & RC & TO & TM & THIC \\
\hline LT & 1 & & & & & & & & & & & & & & \\
\hline WT & 0.588 & 1 & & & & & & & & & & & & & \\
\hline RT & -0.696 & -0.819 & 1 & & & & & & & & & & \\
\hline EMT & 0.202 & $\mathbf{0 . 9 0 6}$ & -0.623 & 1 & & & & & & & & & & & \\
\hline G & 0.745 & 0.223 & -0.449 & -0.147 & 1 & & & & & & & & & & \\
\hline 2HG & 0.702 & 0.159 & -0.367 & -0.201 & $\mathbf{0 . 9 9 2}$ & 1 & & & & & & & & & \\
\hline 2HG5 & 0.770 & 0.181 & -0.411 & -0.204 & $\mathbf{0 . 9 8 3}$ & $\mathbf{0 . 9 7 4}$ & 1 & & & & & & & & \\
\hline B & 0.600 & 0.315 & -0.298 & 0.060 & 0.648 & 0.631 & 0.691 & 1 & & & & & & & \\
\hline 2HB & 0.652 & 0.114 & -0.213 & -0.211 & $\mathbf{0 . 8 4 2}$ & $\mathbf{0 . 8 5 5}$ & $\mathbf{0 . 8 6 8}$ & $\mathbf{0 . 8 9 3}$ & 1 & & & & & & \\
\hline LC & 0.302 & 0.018 & -0.084 & -0.146 & 0.527 & 0.531 & 0.528 & 0.069 & 0.207 & 1 & & & & & \\
\hline WC & -0.128 & -0.287 & 0.314 & -0.311 & 0.272 & 0.325 & 0.199 & -0.247 & 0.027 & 0.422 & 1 & & & & \\
\hline RC & -0.180 & 0.003 & 0.136 & 0.127 & -0.363 & -0.368 & -0.299 & -0.167 & -0.301 & -0.064 & -0.402 & 1 & & & \\
\hline TO & -0.683 & -0.312 & 0.543 & 0.007 & -0.820 & -0.794 & -0.821 & -0.684 & -0.742 & -0.476 & 0.189 & 0.266 & 1 & & \\
\hline TM & -0.670 & -0.268 & 0.572 & 0.072 & -0.799 & -0.753 & -0.784 & -0.541 & -0.658 & -0.232 & -0.019 & 0.582 & 0.801 & 1 & \\
\hline THIC & -0.794 & -0.415 & 0.640 & -0.057 & -0.805 & -0.756 & -0.811 & -0.701 & -0.729 & -0.238 & 0.132 & 0.470 & $\mathbf{0 . 8 4 0}$ & $\mathbf{0 . 9 4 2}$ & 1 \\
\hline
\end{tabular}

Table 6. Correlation table of measured data on KES system

The principal components analysis (PCA) enables the visualization of linear correlations between the measured data on the KES system. PCA transforms multivariate data into a 
lower-dimensional space where trends and patterns in the data can be detected. It extracts a set of new variables - the so-called principal components (PCs) - that are linear combinations of the original variables. The number of PCs equals the number of variables, however, generally, the first few (two or three) PCs already account for most of the variability in the data. By plotting two PCs, the relationships among the samples as well as among the studied variables can be visualized (Zupin et al, 2009).

From the correlation Table 6 and Figure 12 below, it can be seen that between the mechanical properties measured on the KES system, positive and negative correlations exist. The surface properties (MIU, MMD and SMD) and mass per square meter are not included into the PCA analysis. The surface properties are mostly influenced by weave, which makes the structure and surface of fabrics. Mass per square metre is almost the same at all fabrics, since the set density is the same at all fabrics.

From the correlation Table 6 and Figure 12 where close proximity, clustering, of points suggests that a high degree of positive correlation exists among the linearity of tensile loadextension curve (LT) and shear properties of fabrics (G, 2GH, 2GH5); tensile energy per unit area (WT) and extensibility (EMT); shear rigidity (G) and shear hysteresis (2HG, 2HG5) and bending properties $(\mathrm{B}, 2 \mathrm{HB})$. This result was expected, for the shear and bending properties are highly related, both influenced by construction parameters of fabrics, esp. yarn properties and weave. Bending and shear properties are the most important properties for explaining the fabric stiffness, hardness and tailorability (Lam, Postle, 2006). It is also known that tensile work and extensibility correlate with each other.

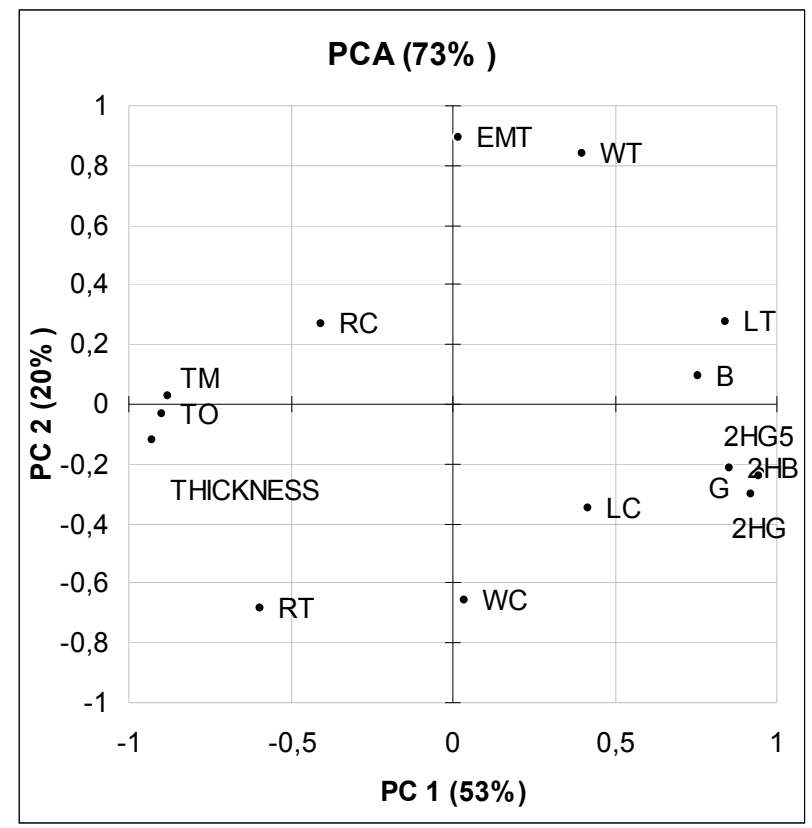

Fig. 12. Plot of original variables in PC1-PC2 coordinate system made with multivariate statistical method PCA, which presents correlations between mechanical properties measured on KES evaluation system 


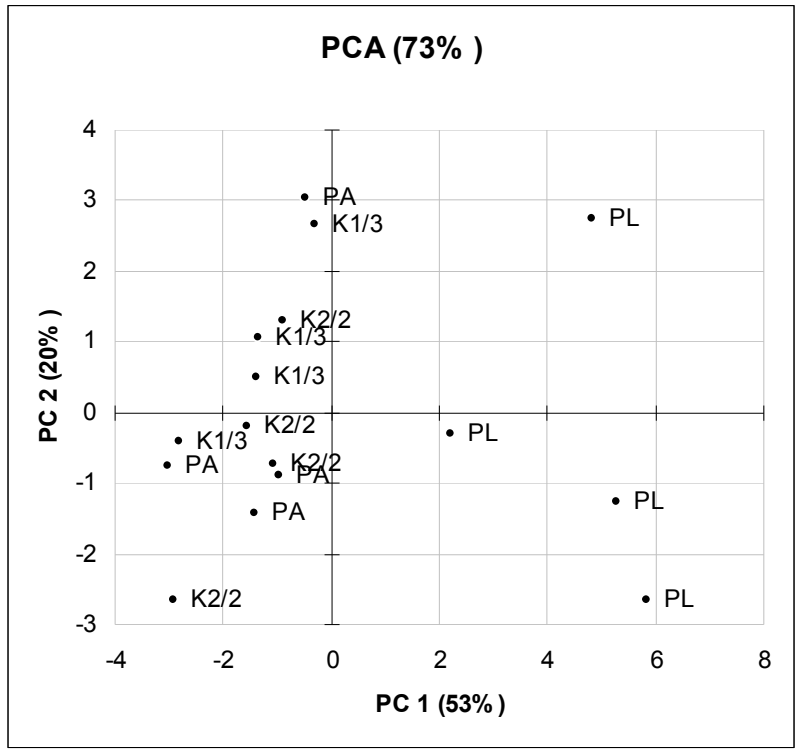

Fig. 13. Plot of 16 fabrics samples in PC1-PC2 coordinate system, each data label representing particular weave type

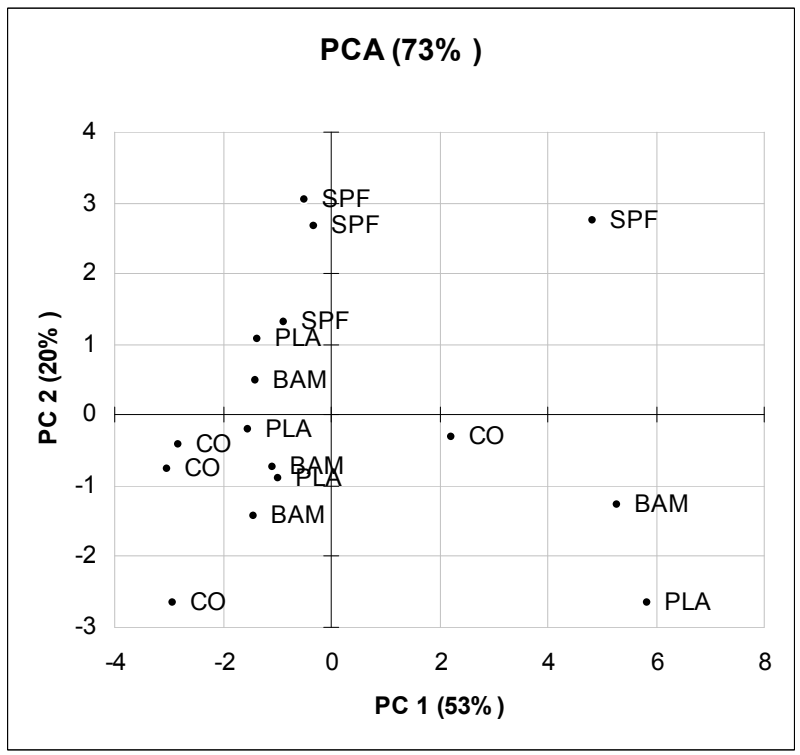

Fig. 14. Plot of 16 fabrics samples in PC1-PC2 coordinate system, each data label representing particular material used in weft 
A strong negative correlation is observed where the points are opposite each other. A high degree of negative correlation exists among the linearity of tensile load-extension curve (LT) and thickness of fabrics; tensile energy per unit area (WT) and tensile resilience (RT); thickness of fabrics and shear $(\mathrm{G}, 2 \mathrm{GH}, 2 \mathrm{GH} 5)$ and bending $(\mathrm{B}, 2 \mathrm{HB})$ properties. These findings are expected, since the higher the fabric thickness, the harder it is to bend and shear the material. A negative correlation is also expected between WT and RT, for the more the fabric extends, the more energy is required to extend the fabrics to the final extension percentage.

In Figure 13, it can be seen that the fabrics made in plain wave (PL) have different properties than all other fabrics, as has already been discussed. And Figure 14 shows that fabrics are clustered according to different material used in weft.

\section{Conclusion}

From the research results, it can be seen how different materials used in weft influence the mechanical properties of fabrics. The highest breaking force in warp direction is exhibited in the fabrics with the highest tensile elongation: SPF, PLA and bamboo yarn, followed by the fabrics with cotton yarn in weft. The material used in weft has almost no influence on the breaking elongation in warp direction; it is influenced almost only by weave. In weft direction, cotton fabrics have the highest tensile force, whereas lower tensile strength is observed in the fabrics with PLA, SPF and bamboo wefts. The materials also have the highest influence on the tensile elongation of fabrics in weft direction. Each yarn selected in weft has its own specific properties, which is reflected in the fabric.

It was established that all fabrics in weft direction have elongation from 20 to $45 \%$, which is completely suitable to use as a fabric with increased elasticity.

It can also be seen that different weave types also influence fabric properties; however, their influence is lower.

The research of other mechanical properties measured with the KES system shows that fabrics with SPF yarn in weft are the most extensible and flexible, while the fabrics with cotton and bamboo in weft have higher tensile resilience than the fabrics with PLA and SPF in weft. Fabrics with PLA in weft are the stiffest and the most rigid, while the cotton fabrics are the softest.

In general, it can be claimed that fabrics with PLA, SPF and bamboo yarn in weft have a lower tensile force in comparison with pure cotton fabrics but higher tensile elongation in comparison with pure cotton fabrics. The tensile elongation or extensibility of fabrics is an important property for comfortable feeling when wearing clothes.

With the help of multivariate statistical analysis, the correlation between the measured mechanical properties on the KES system was established. Good positive correlation can be seen between shear and bending properties, and between tensile work and extensibility, while good negative correlation is seen between thickness and shear, and bending properties.

In the future researches, apart from the mechanical properties, we would like to research permeability properties of fabrics made with biodegradable material in weft and cotton in warp, inter alia air permeability, water vapour permeability, thermal resistance of fabrics and permeability of UV rays.

Moreover, we would like to test the mechanical and permeability properties of woven fabrics made from $100 \%$ biodegradable fibres (bamboo, PLA or SPF) and compare the properties with presented samples. Nevertheless, for a successful weaving of biodegradable 
yarns in warp, it would be necessary to determine the behaviour of warp yarns in the weaving process, since, as it can be seen from the research, these yarns have high extensibility, i.e. from 8.5 to $27.5 \%$, and not very high strength in comparison with cotton yarns.

It would also be interesting to test how the biodegradable materials act in other application as knittings and nonwovens.

For a more frequent use of biodegradable materials, various constructions, woven and knitted fabrics, and nonwovens should be tested and fabric properties and behaviour after the wearing, usages and after caring, e.g. washing and ironing, should be determined.

\section{Acknowledgements}

I would like to thank Prof. Dr. Manuela Neves from the University of Minho, Portugal, for providing us with the yarns and woven samples used in this research.

\section{References}

Rijavec, T., Bukošek, V. (2009). Novel Fibres for the 21st Century. Tekstilec, Vol. 52, No.1012/2009, 312-327, ISSN 0351-3386

Blackburn, R. S. (2005). Biodegradable and sustainable fibres, Woodhead Publishing, ISBN 185573-916-x, Cambrige England

Brooks, M. M. (2005). Soya bean fibres - past, present and future, In: Biodegradable and sustainable fibres, Blackburn, R. S. (Ed.), 389-440, Woodhead Publishing, ISBN 185573-916-x, Cambrige England

Farrington, D. W., Lunt, J., Davies, S., Blackburn, R. S. (2005). Poly(lactic acid) fibres, In: Biodegradable and sustainable fibres, Blackburn, R. S. (Ed.), 389-440, Woodhead Publishing, ISBN 1-85573-916-x, Cambrige England

Dugan, J.S. (2000). Novel properties of PLA fibres Vice President. Research Fiber Innovation Technology. Inc. Available on-line: http://www.fitfibers.com/files/ PLA\%20Fibers.doc

Das, S. (2010). Properties of bamboo fibres. [citated 25.3.2010]. Available on -line: http://www.fibre2fashion.com/industry-article/textile-industryarticles/properties-of-bamboo-fibre/properties-of-bamboo-fibre1.asp

Netravali, A.N. (2005). Biodegradable natural fiber composites, In: Biodegradable and sustainable fibres, Blackburn, R. S. (Ed.), 389-440, Woodhead Publishing, ISBN 185573-916-x, Cambrige England

Rekha, R., Purnima, D. C. (2004). Biodegradable Polylacitic Acid Polymers for Textile Applications. Man-made Textiles in India. February 2004, 42-44, ISSN:0377-7535

Lou, C.W. et al (2008). Manufactering and Properties of PLA Absorbable Surgical Suture. Textile Research Journal, Vol. 78, No.11, 958-965, ISSN 0040-5175

Yi-you, L. (2004) The soybean protein fibre - A healthy \& comfortable fibre for 21st century. Fibres $\mathcal{E}$ Textile in Eastern Europe. Vol. 12, No. 2 (46), 8-9, ISSN 1230-3666

Realff, M.L., Boyce, M.C, in Backer, S. (1997) A Micromechanical Model of the Tensile Behavior of Woven Fabric. Textile Research Journal, Vol. 67, No. 6, 445-459, ISSN 0040-5175

Grosberg, P. (1969). The tensile properties of woven fabrics. In: Structural Mechanics of Fibres, Yarns and Fabrics. Volumne 1. ,John Wiley\&Sons, 339-354, ISBN 471-36669-2 
Saville, B. (2002). Physical testing of textiles. Woodhead Publishing and CRC Press, ISBN 185573-367-6, Cambridge

Gabrijelčič, H., Černoša, E. in Dimitrovski, K. (2008). Influence of weave and weft characteristics on tensile properties of fabrics. Fibres $\mathcal{E}$ textiles in Eastern Europe, Vol. 16, No. 2 (67), 45-51, ISSN 1230-3666

Geršak, J. (2006). Mehanske in fizikalne lastnosti tekstilnih materialov. Fakulteta za strojništvo, Laboratorij za oblačilno inžinerstvo ter fiziologijo in konstrukcijo, ISBN 86-4350754-7, Maribor

Hu, J. (2004). Structure and mechanics of woven fabrics. Woodhead Pub., ISBN 0-8493-2826-8, Cambridge

Realff, M. L., Seo, M. H., Boyce, M. C., Schwartz, P., and Backer, S. (1991). Mechanical properties of fabric woven from yarns produced by different spinning technologies : yarn failure as a function of gauge length. Textile Research Journal, Vol. 61, No. 9, 517-530, ISSN 0040-5175

Brooks, M. M. (2005). Soya bean fibres - past, present and future, In: Biodegradable and sustainable fibres, Blackburn, R. S. (Ed.), 389-440, Woodhead Publishing, ISBN 185573-916-x, Cambrige England

Kawabata, S. (1989). Nonlinear mechanics of woven and knitted materials, Textile Structural Composites, Chou, T. W. and Ko, F. K. (Ed.), Elsevier Science Publisher, 67-116, ISBN 0-444-42992-1, Amsterdam

Zupin, Ž., Dimitrovski, K. (2008). Tensile properties of fabrics made from new biodegradable materials (PLA, soybean, bamboo fibres). Proceedings of Magic world of textiles, pp. 185-190, ISBN 978-953-7105-26-6, Dubrovnik, Croatia, October, 2008, Faculty of Textile Technology, University of Zagreb, Zagreb

Pierce, F.T. (1937). The geometry of cloth structure. The Journal of the Textile Institute, Vol. 28, No. 3, T45-T96, ISSN 0368-4474

Womersley, J.R. (1937). The application of differential geometry to the study of the deformation of cloth under stress. The Journal of the Textile Institute, Vol. 28, No. 3, T97-T112, ISSN 0368-4474

Zupin, Ž., Dimitrovski, K., Hladnik, A. (2009). Determination of woven fabrics influential parameters using multivariate statistics. Proceedings of the 9th Autex Conference, pp. 585-590, ISBN 978-975-483-787-2, Izmir, Turky, May, 2009, Ege University, Engineering Faculty, Department of Textile Engineering, Izmir

Lam, J.K.C., Postle, R. (2006). Multivariate Studies of Mechanical Properties for Wool and Cotton Fabrics. Textile Research Journal, Vol. 76, No. 5, 414-425, ISSN 0040-5175

Chan, C.K. et al (2006). Evaluation of mechanical properties of uniform fabrics in garment manufacturing. Journal of Materials Processing Technology, Vol. 174, 183-189, ISSN 0924-0136

Kemp, A. (1958). An extension of Peirce's cloth geometry to the treatment of non-circular theads. The Journal of the Textile Institute, Vol. 49, No. 1, T44-T48, ISSN 0368-4474

Olofsson, B. (1965). A general model of a fabrics as a geometric-mechanical structure. The Journal of the Textile Institute, Vol. 55, No. 11, T541-T557, ISSN 0368-4474 


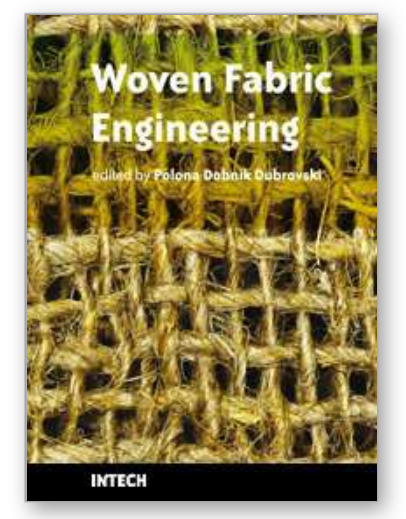

\author{
Woven Fabric Engineering \\ Edited by Polona Dobnik Dubrovski
}

ISBN 978-953-307-194-7

Hard cover, 414 pages

Publisher Sciyo

Published online 18, August, 2010

Published in print edition August, 2010

The main goal in preparing this book was to publish contemporary concepts, new discoveries and innovative ideas in the field of woven fabric engineering, predominantly for the technical applications, as well as in the field of production engineering and to stress some problems connected with the use of woven fabrics in composites. The advantage of the book Woven Fabric Engineering is its open access fully searchable by anyone anywhere, and in this way it provides the forum for dissemination and exchange of the latest scientific information on theoretical as well as applied areas of knowledge in the field of woven fabric engineering. It is strongly recommended for all those who are connected with woven fabrics, for industrial engineers, researchers and graduate students.

\title{
How to reference
}

In order to correctly reference this scholarly work, feel free to copy and paste the following:

Ziva Zupin and Krste Dimitrovski (2010). Mechanical Properties of Fabrics Made from Cotton and Biodegradable Yarns Bamboo, SPF, PLA in Weft, Woven Fabric Engineering, Polona Dobnik Dubrovski (Ed.), ISBN: 978-953-307-194-7, InTech, Available from: http://www.intechopen.com/books/woven-fabricengineering/mechanical-properties-of-fabrics-made-from-cotton-and-biodegradable-yarns-bamboo-spf-pla-inweft

\section{INTECH}

open science | open minds

\author{
InTech Europe \\ University Campus STeP Ri \\ Slavka Krautzeka 83/A \\ 51000 Rijeka, Croatia \\ Phone: +385 (51) 770447 \\ Fax: +385 (51) 686166 \\ www.intechopen.com
}

\author{
InTech China \\ Unit 405, Office Block, Hotel Equatorial Shanghai \\ No.65, Yan An Road (West), Shanghai, 200040, China \\ 中国上海市延安西路65号上海国际贵都大饭店办公楼 405 单元 \\ Phone: +86-21-62489820 \\ Fax: $+86-21-62489821$
}


(C) 2010 The Author(s). Licensee IntechOpen. This chapter is distributed under the terms of the Creative Commons Attribution-NonCommercialShareAlike-3.0 License, which permits use, distribution and reproduction for non-commercial purposes, provided the original is properly cited and derivative works building on this content are distributed under the same license. 